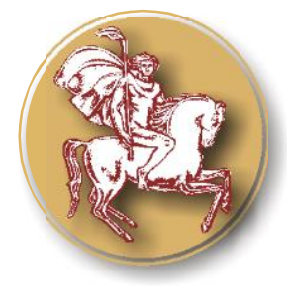

Trakia Journal of Sciences, No 4, pp 314-328, 2021

Copyright (C) 2021 Trakia University

Available online at:

http://www.uni-sz.bg

ISSN 1313-3551 (online)

doi:10.15547/tjs.2021.04.005

Original Contribution

\title{
HUMAN RESOURCES AS MAIN FACTOR FOR THE DEVELOPMENT OF HEALTH TOURISM IN BULGARIA
}

\author{
S. Dimitrov ${ }^{1 *}$, T. Dimitrova ${ }^{2}$ \\ ${ }^{1}$ Departament of Tourism, Faculty of Economics, ,St. Cyril and St. Methodius” University of Veliko \\ Tarnovo, Bulgaria \\ ${ }^{2}$ Department of Business Administration, Faculty of Economics, „St. Cyril and St. Methodius” University \\ of Veliko Tarnovo, Bulgaria
}

\begin{abstract}
Modern tourism is a complex socio-economic and cultural phenomenon of multifaceted significance. Apart from the traditional types of tourism, the modern (alternative, traditional) types of tourism are becoming more and more attractive. One of them is health tourism. Health tourism covers the following subtypes of tourism: balneo, spa and wellness, thalassotherapy and medical. Its development on a global, European and national scale is considered. In Bulgaria there are excellent conditions for its development. The role of human resources in relation to health tourism is also growing. Their personnel development, education and training are monitored. The index of specialization allows to establish what is the health and tourism specialization and the opportunities for overcoming the existing disparities in terms of staffing.
\end{abstract}

Key words: Health tourism, balneal tourism, spa tourism, medical tourism, human resources.

\section{INTRODUCTION}

Modern tourism is a complex socio-economic and cultural phenomenon of multifaceted significance. Apart from the traditional types of tourism, the modern (alternative, traditional) types of tourism are becoming more and more attractive. One of them is health tourism. The term „health tourism“ means: „Any journey by people outside their place of residence for the purpose of improving, restoring or treating the health and physical condition of an individual through the spa, balneological, therapeutic or medical services". Health tourism covers the following subtypes of tourism:

\footnotetext{
*Correspondence to: Professor Slavi Petrov Dimitrov PhD, Departament of Tourism, Faculty of Economics, ,St. Cyril and St. Methodius” University of Veliko Tarnovo, Bulgaria, (1, Arch. Georgi Kozarev str., Veliko Tarnovo 5000), GSM 0887394173,s.dimitrov@ts.uni-vt.bg
}

- Balneo, understood as: tourism related to effective treatment and rehabilitation under medical control, through mineral water, healing mud, and others;

- Spa and wellness, understood as: tourism related to relaxation and comfort procedures for body and soul, based on various natural resources and products (mineral water, essential oils, healing mud, wine, chocolate, etc.);

- Thalassotherapy, understood as: tourism near the sea, associated with programs and rituals involving the use of sea water and /or natural derivatives, and/ or estuarine mud, through classical and non-traditional therapeutic methods of exposure aimed at restoring psycho-emotional and physical health, as well as focused on the beauty of the human body, which are held in specialized offices, halls and premises;

- Medical tourism, understood as: tourism whose main purpose is to improve or restore health through medical intervention (1). 


\section{METHODOLOGY OF THE RESEARCH}

The subject of research is health tourism and the need to provide it with professional staff. The object of study is the health tourism in Bulgaria and the opportunities for training of qualified personnel related to its functioning. The purpose of the analysis is to provide a comprehensive understanding of the development of health tourism in Bulgaria and the opportunities for its staffing. The methods used are theoretical analysis and synthesis, historiographical methods, convergent analysis and graphical methods. The Localization Index is used, which is an important indicator in the analysis in tourism, along with a number of other mathematical methods and models. It helps to find the place of tourism in the system of the local, regional or national economy.

In recent years there have been a number of studies related to the development of health tourism in Bulgaria: Stankova (2006) (2); Yordanov (2008) (3); Shishmanova (2011) (4); Vasileva (2012) (5); Rizova (2013) (6); Kazandzhieva (2014) (7); Stoynev (2015) (8); Spasova (2016) (9); Stoyanova (2016) (10); Staykov and Georgieva (2018) (11); Vladeva (2018) (12); Veselinova (2021) (13); Belichenova (2021) (14). The topic is touched upon in a number of strategic documents concerning the development of this type of tourism in Bulgaria, such as the Concept for tourist zoning of Bulgaria, 2015; Updated National Strategy for Sustainable Development of Tourism in the Republic of Bulgaria, 20142030 (15) and others.

\section{DEVELOPMENT OF HEALTH TOURISM IN THE WORLD, EUROPA AND BULGARIA}

\section{DEVELOPMENT OF HEALTH TOURISM WORLDWIDE AND EUROPEAN}

Tourism is one of the world's largest industries, accounting for one tenth of the world's GDP and employment. In 2019, international arrivals reached 1.459 billion $(+3.7 \%)$ and revenues were 1.7 trillion. dollars $(+4.4 \%)$ (16). The forecasts for significant growth in the following years were refuted by the consequences of the KOVID-19 epidemic.

Health tourism, with its forms of spa, wellness and medical tourism, has been growing steadily
DIMITROV S., et al. in recent years and has become increasingly relevant in many established and emerging destinations around the world. Globally, the health tourism segment is still not well defined, with differences based on geographical and linguistic characteristics and a wide variety of related cultural traditions, with data on specific forms of health tourism being fragmented and limited. In parallel, various sources estimate its market value at $\$ 45.5$ billion up to $\$ 72$ billion, its annual growth reaches 10-12\%.

The World Tourism Organization and the European Travel Commission define health tourism as an emerging global segment of tourism that is changing rapidly and needs to be properly understood, studied and exposed in order to meet the challenges, develop and contribute on the well-being of people and economies around the world (17).

The share of health tourism worldwide is not specified. For the wellness and spa markets, the Global Wellness Index (GWI) forecasts that the share of primary and secondary travel is about $7 \%$ of all global domestic and international tourist trips in 2017, with wellness trips in the country permanently living ahead of international $(83 \%$ and $17 \%$ respectively). Primary wellness / spa trips account for $0.8 \%$ of all global trips. According to GWI, the European share of all domestic and international wellness and spa trips is $39 \%$. In terms of total international arrivals, the EU-27 market accounts for about 59\% of the world market. The EU's share of health-related international tourism is also $1.6 \%$, significantly higher than in the rest of the world at $0.9 \%$.

According to Grand View Research, the global medical tourism market is estimated at \$36.9 billion. . in 2019 and is expected to increase by $21.9 \%$ by 2026 . The presence of favorable factors such as better health care, innovative medicines, modern equipment, better hotel services and personalized care are crucial for this market. Better access to a qualified professional at a lower cost is a major reason to travel for medical purposes. The market is expected to grow rapidly by 2026 .

Within the EU-27, a total of 56 million domestic and 5.1 million international trips were made in 2019. The share of tourist trips for health is small 
- only $4.3 \%$ of all visits. Only $5.8 \%$ of all domestic visits and only $1.1 \%$ of all international visits are for this purpose. Revenues from health tourism amount to around $€ 47$ billion, representing $4.6 \%$ of total tourism revenues and $0.33 \%$ of EU-27 GDP. The seasonality of health tourism is different from general tourism and is less pronounced. Health tourism actually counteracts the average seasonality in tourism in general. The share of arriving health tourists is about $6 \%$ (18).

It should also be noted that much of the data on the health tourism market relates mainly to medical tourism. This is largely due to the European Directive 2011/24 on cross-border healthcare, adopted in 2011, according to which Member States must ensure free access to treatment throughout the EU for all its citizens (19).

This necessitates trained experts to offer professional customer service. European requirements contribute to the standard offer of this type of services not only for Bulgarian tourists, but also internationally.

\section{HEALTH TOURISM IN BULGARIA}

Health tourism is among the rapidly developing specialized forms of tourism of growing importance for national and local economies. As a country with long traditions in the development of tourism, balneotherapy and medicine, Bulgaria has a good potential for complex development of all areas in health tourism.

Currently, there is a lack of reliable data on the share of health tourism within not only the Bulgarian but also the European tourism sector. An EP report states that Bulgaria, along with Finland, Ireland, Spain and Germany, has a high share in the offer of wellness holidays, but lags behind other countries in Central and Eastern Europe, where along with the Spanish and Baltic coasts it has the highest density of accommodation for health tourism.

The same report states that the share of health tourism in the Bulgarian tourism product is $9 \%$ in domestic and $1.1 \%$ in foreign tourism, which in absolute terms represents 290 thousand arrivals of domestic tourists and 80 thousand arrivals of foreign tourists. Revenues from the arrival of
DIMITROV S., et al domestic tourists amount to EUR 40 million and to foreign tourists - EUR 30 million (20).

The level of development of the tourist product for Balneo, spa and wellness tourism is relatively high - in second place among the specialized types of tourism after cultural tourism with $6.6 \%$ of all tourist products and services in Bulgaria. The products offered in this type of tourist activity are not mass and unified. There is a possibility for their individualization according to the needs of each tourist. Each hotel offers different products, and travel agents only offer accommodation with packages prepared by hotel specialists (21). Customer requirements are growing, which obliges hoteliers to provide professionals with a professional focus in the field of health tourism.

According to the study, spa and balneotourism ranks second in practice (among specialized forms of tourism) by foreign tourists with $26.5 \%$, behind the cultural by $35 \%$ and with the same share as eco-tourism (26.5\%).

The review of global and European trends shows that there are good opportunities for Bulgaria to take advantage of global and European positive factors that affect the development of health tourism.

First of all, the country has a good geographical location and natural resources that allow for the development of all forms of health tourism.

In some respects, Bulgaria can catch up at a very fast pace in terms of supply, such as in the field of spa tourism, where a significant share of unused natural resources and superstructure are available, which can accommodate an increased number of tourists, but must be partially or completely renovated.

Also, in wellness tourism there is significant potential, as in Bulgaria there are a large number of locations with very attractive natural resources that can be used mainly for wellness tourism.

Thalassotherapy tourism also has potential, especially in terms of the „full package“ of usable resources, because the Black Sea coast of Bulgaria has optimal data in terms of sea water, sand, purity and quality of air, the availability of seafood and peloids. In all the above areas, the 
country has a high potential to offer a competitively balanced price-quality product.

In the field of medical tourism, there is potential due to the good level of specialists and medical equipment in certain areas, but the country is under strong competitive pressure. Statistically, there is a significant resource such as accommodation and specialists, but the national health insurance system could be put under serious pressure if the orientation of medical institutions to medical tourism becomes a priority (22).

The use of natural „healing“ resources has been known since ancient times. The richness and diversity of the hot mineral springs in the Bulgarian lands, the clean air, and the forests have presupposed the development of the early forms of health tourism in our country. Many of the modern resorts and tourist sites are located in places rich in mineral springs, whose beneficial effects on human health and well-being have been evaluated by scientists and researchers.

The healing properties of the mineral waters of Bulgaria are those that attract foreigners and are a prerequisite and resource for the development of the infrastructure of balneological tourism in the country. Until the 1940s, a number of settlements with healing mineral water resources developed their material base for the construction and development of spa tourism in Bulgaria. They are expanding and improving, as at the beginning of the century the best landscaped were the Haskovo Mineral Baths, and later the Sliven Mineral Baths, Pavel Banya, Gorna Banya, Varshets. In 1929 a „Balneological Society" was established, which has the task of putting the resort business in the country on a scientific basis.

After the middle of the 60's and 70's of the 20th century a strong process of centralization and formation of a state monopoly in the tourist activity in our country began. In 1969, the merger of "Balkantourist" and „Rodina“ formed „Balkantourist“. In 1971 „Balkantourist“ merged with „Tourist“, becoming the only institutional monopoly in the field of tourism in our country. Gradually, throughout the period, the regulations for health tourism in Bulgaria began to be built and improved (23).

The normative acts related to health tourism have undergone significant changes in the last few
DIMITROV S., et al. years and follow the diversification of the forms of health tourism in our country. Developing in the beginning mainly as balneological, its modern dimensions according to the current Tourism Act of 2013 are related to the development of medical SPA centers, wellness centers and thalassotherapy centers. This creates preconditions for the formation of a new legal framework related to the provision of SPA, wellness, thalassotherapy services in certified balneotherapy (medical SPA), wellness and thalassotherapy centers.

With the development of the concept for sustainable development of tourism, embedded for the first time in the optimized state policy in the field of tourism through the National Strategy for Sustainable Tourism Development in Bulgaria 2009-2013, the sustainable development of health tourism (balneology, SPA, wellness), which is displayed as a priority. The national strategy outlines the high competitiveness of the natural potential for the development of health tourism - over 600 mineral water sources, grouped in about 240 deposits, $75 \%$ of which are warm and hot - with a temperature of 37-101 degrees Celsius; almost all types of mineral waters found in the world; healthy climate with healing effect in certain regions of the country; availability of modern balneo and SPA-hotels not only on the Black Sea coast, but also in the interior of the country, established traditions in balneotherapy, 142 resorts, of which 58 balneotherapy, 56 mountain climatic and 28 sea resorts.

Even then, the need arose for health tourism to become a state policy by regulating the status, construction, equipment and furniture, services provided, requirements for the staff of balneo, SPA and wellness centers; by introducing standards for the offered services, improving the mechanisms of interaction between the institutions, offering health programs as part of the overall tourist entertainment program, developing a policy of encouraging employers in tourism to invest in the formation of new professional skills, training and qualification of personnel in the field of health tourism; as well as building a system of events to promote and promote health tourism in general.

In 2013, based on a health policy strategy, the first health cluster in Bulgaria was opened at the initiative of the Bulgarian Medical Union, which is 
the basis for reporting on regional health features. Among the priorities of the cluster is the development of medical tourism. The main goal of the first health cluster in the country is to form longterm goals of health policies and increase the quality of medical care.

Bulgaria has made very serious progress in a number of medical specialties such as microvascular surgery, liver surgery, invasive cardiology and others, there are highly qualified specialists, and highly specialized medical equipment, fast and easily accessible services at good prices. Despite the excellent resources, traditions and culture in balneology, however, Bulgaria does not have a clear program for strategic development, and a well-formed product (especially in medical tourism) to offer in the international arena.

In the current Updated National Strategy for Sustainable Development of Tourism in the Republic of Bulgaria 2014-2030 in the analysis of the product of health tourism it is emphasized that its form of medical tourism is ,completely underestimated", despite the available prerequisites for its development (24).

Bulgaria not only does not have a well-functioning system, but it does not have a system in place for purposefully focused and consistent attraction of foreign patients in the country for various forms of health tourism. In the recent historical plan, there have been some efforts on the part of the state (institutions responsible for tourism and health policy in Bulgaria), and these efforts have seen visible success mainly in spa, spa and wellness tourism. The development of health tourism is largely linked to staffing, education and training.

\section{EDUCATION AND TRAINING OF STAFF WORKING IN THE FIELD OF HEALTH TOURISM}

\section{STAFFING}

Providing human resources in the field of health care is a logistical task of great complexity. Along
DIMITROV S., et al

with long-term planning in a dynamic environment at the national and international level, an important resource must be sought in ensuring a close link between training, formal employment and actual responsibilities. On the one hand, to provide conditions for adaptability to the labor market, and on the other hand - to obtain the competencies needed to manage innovation and new technologies in health care, including the entry of artificial intelligence. The inability to supply labor in response to human resource needs leads to labor market imbalances.

As early as 2003, a World Health Organization report stated that ,the most critical problem facing the world's health systems is the shortage of people to work in those systems" (25). There is currently a shortage of nurses globally, especially nurses. This is thought to be due to the lack or presence of negligible investment in nursing training, inadequate pay, work environment and management, the growing international migration process, and the fact that nurses are leaving nursing and moving to other professions. The mobility of health professionals, as well as users of health services in the EU, further complicates planning at national level (26).

At the end of 2020, 29,717 doctors practiced on a basic employment contract in the medical and healthcare institutions in the country (Table 1), which is an increase of $0.2 \%$ compared to 2018 and an increase of $6.1 \%$ compared to 2010 .

At the end of 2020, there were 7,312 dentists, which is an increase of $1.0 \%$ compared to 2018 and an increase of $13.1 \%$ compared to 2010 . According to the National Statistical Institute (NSI), 6,347 dentists medicine work in practices that have a contract with the National Health Insurance Fund (NHIF).

Table 1. Medical staff, cash (2010-2020)

\begin{tabular}{|c|c|c|c|c|}
\hline & 2010 г. & 2017 г. & 2018 г. & 2020 r. \\
\hline Doctors & 27997 & 30078 & 29667 & 29717 \\
\hline Dentists & 6355 & 8355 & 7240 & 7312 \\
\hline $\begin{array}{l}\text { Medical specialists in } \\
\text { health care }\end{array}$ & 47468 & 46702 & 46332 & 44676 \\
\hline \multicolumn{5}{|l|}{ Population } \\
\hline To some doctor & 268 & 234 & 236 & 233 \\
\hline To a dentist & 1181 & 844 & 967 & 946 \\
\hline
\end{tabular}

Source: NSI, 2021. 
In 2020, a total of 29,717 medical doctors work in Bulgaria, which ranks the country 14th in the number of doctors in the EU. In terms of the number of doctors per 100,000 populations in 2020, Bulgaria ranks fourth in the EU-28 after Germany (418), Lithuania (447), Austria (512). If for the period 2010-2020 in Bulgaria the number of practitioners has increased by $6.1 \%$, then for other countries the growth is impressive - Cyprus (30\%), Slovenia (24\%), Malta (24.2\%), Romania (19.9\%), Latvia (16.6\%), Croatia (16\%). Germany also achieves higher growth than Bulgaria (12.2\%) (27).

In terms of the number of dentists per 100,000 inhabitants, Bulgaria, together with Greece and Cyprus, ranks one of the top in the EU-27 (2-16 years) with 112.4 or a total of 7,312 (28).

Greece alone has a higher number of dentists per 100,000 inhabitants (122.7) and a total of 13,225,
DIMITROV S., et al. while Cyprus follows Bulgaria with a total of 882 doctors or 103.6 per 100,000 inhabitants. The lowest values in 2020 are observed in Poland (33.2), Malta (47), Slovakia (49.7), Great Britain (53.2), the Netherlands (54.8), Austria (56.7).

There are 44,676 medical health care specialists in Bulgaria at the end of 2020, of which 29,160 are nurses and 3,251 are midwives.

An important indicator in terms of predictability of staffing is the distribution of medical staff by age groups. In Bulgaria at the end of 2020 the largest share of doctors is in the age group 55-64 years - 10,387, or $34.9 \%$ of all practitioners. Young practitioners - up to 35 years are 3,757 or $12.6 \%$, and the oldest (aged 65 and over) - 4,865 or $16.3 \%$. Bulgaria is not lagging behind the trend of rapid aging of the healthcare workforce valid for the EU.

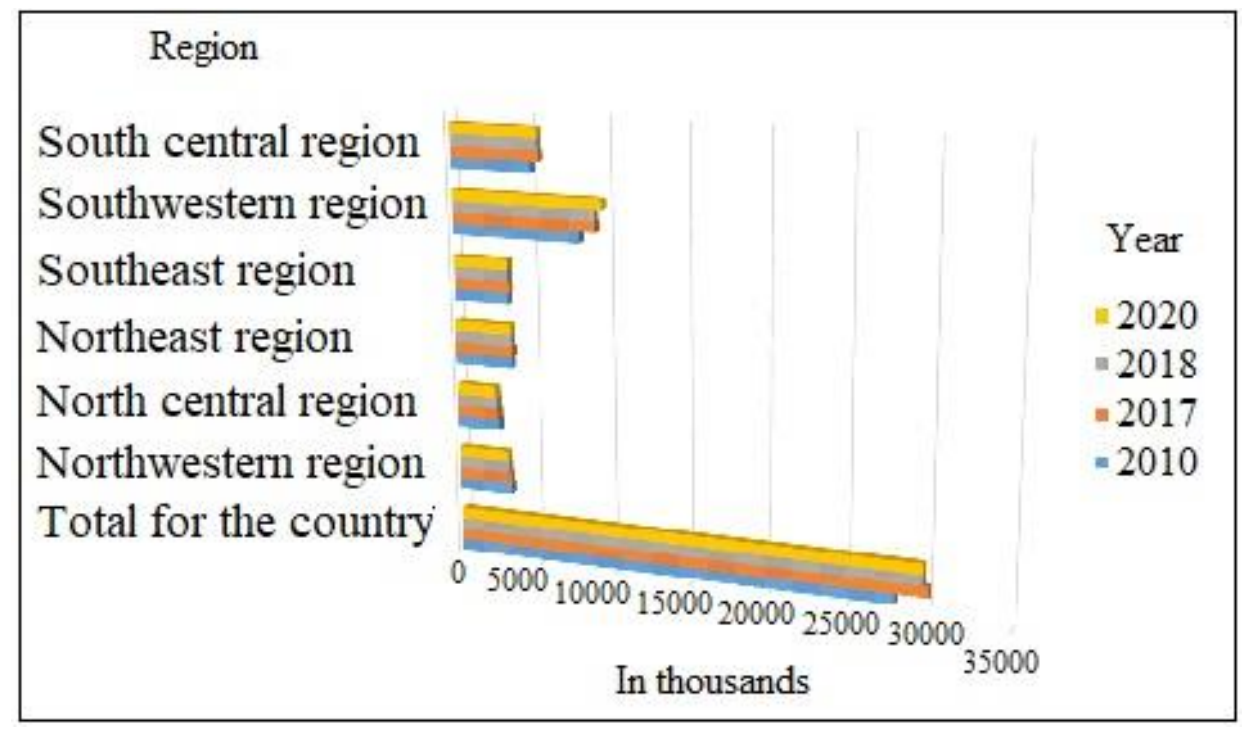

Figure 1. Practitioner's doctors in Bulgaria (2010 - 2020)

Own production. Source: NSI, 2021

The territorial distribution of doctors in Bulgaria is relatively balanced in relation to the number of inhabitants. Of the total of 29,717 doctors practicing in Bulgaria in 2020, 10.9\% are in the North-West region, $8.6 \%$ - in the North-Central region, $12.4 \%$ - in the North-East region, $11.9 \%$ in the South-East region, $19.3 \%$ - in the South Central region and $33.1 \%$ - in the Southwest region (Figure 1).
In the structure of doctors by specialties at the end of 2020 the largest share of general practitioners is $14.2 \%$ of all doctors in the country, followed by: Obstetrics and Gynecology and Cardiology - 5.9\% each, Pediatrics - 5.8\%, Anesthesiology and Intensive Care - 5.6\%, Surgery $-5.3 \%$ and Nervous diseases $-5.0 \%$

According to Ordinance №2 of 29.01.2016 on the terms and conditions of certification of 
„Balneotherapy (medical SPA) center“, „SPA center", „Wellness center" and „Thalassotherapy center" the following specialists are needed for the work of the centers:

- For balneotherapy (medical SPA) and thalassotherapy center: manager - a person who meets the requirements of the Medical Establishments Act for the respective type of medical establishment; head of the medical activity - a doctor with a recognized medical specialty in physical and rehabilitation medicine; medical and non-medical specialists, in accordance with the requirements of Ordinance № 30 of 2004 for approval of the medical standard „Physical and Rehabilitation Medicine“, received their education in accredited higher schools;

- For SPA center: manager - a person with higher education in the professional field "Medicine“, „Public Health“, „Health Care“, „Tourism“ and „Sport"; Medical and non-medical specialists who have received their education in accredited higher schools (at least 1 of the indicated professions): kinesitherapist; rehabilitator; nurse; - For wellness center: manager - a person with higher education in the professional field „Medicine“, „Public Health“, „Health Care“, „Tourism“, „Sports“, „Administration and Management", „Economics" or „Law" and at least 3 years of experience in the provision of services aimed at the health and / or beauty of the human body and at restoring and improving the psycho-physical and emotional state of the individual; medical and non-medical specialists, received their education in accredited higher schools (1 of the indicated professions): kinesitherapist; rehabilitator (29).

NSI data show that in all districts of the country there are specialists in physical therapy and rehabilitation (654 in total). In the period 20102020 their number increased significantly in some regional cities to $200 \%$ (Kardzhali), $166 \%$ (Smolyan), 150\% Blagoevgrad, Silistra, Ruse and Targovishte over $100 \%$. In others, such as Shumen, Dobrich and Kyustendil, it is declining sharply.

There is an unbalanced distribution of doctors by specialties by statistical regions and districts on the one hand, and on the other - the presence of very large fluctuations of doctors by specialties
DIMITROV S., et al

over the years, even within the same statistical region and district.

According to NSI data, the provision with doctors at the end of 2020 is a total of 233 people per 1 doctor, and with dentists - 946 people per population of 1 dentist. This indicator is best in the areas where the centers have medical universities and university hospitals. The lowest number of people per population of a doctor is in the districts of Pleven $(158,2 / 3$ of the national average), followed by Sofia (180), Plovdiv (193), Varna (196). The worst is the provision with doctors in the districts of Razgrad (325), Yambol (318), Targovishte (314), Silistra (294), Vidin (284).

The provision of dentists is the best in Plovdiv (580 - 2/3 of the national average), Sofia (711), Varna (764), Smolyan (828), Pernik (866). The lowest insurance is registered in Sofia (1863 people per doctor), Targovishte (1804), Razgrad (1800), Silistra (1670), Montana (1567).

\section{EDUCATION}

The quality of the product of health tourism is an important prerequisite for the development and establishment of the image of Bulgaria in the international arena. It is formed as a result of a number of conditions and the influence of factors such as resources, legal and regulatory framework, proper marketing strategy, smart management. The human factor is extremely important for the quality and image of health tourism (30). Based mainly on health care, the quality of the product depends on the competencies and management of human resources to a very large extent, as they manage the process of creation, realization and consumption of the product of health tourism.

In the first place are human resources, which relate to health care in general and which are the entrance to the health system. The effectiveness and usefulness of the health system largely depends on the knowledge, skills and motivation of those responsible for providing health services. At the same time, the factors that create them include the size, composition and distribution of the health workforce, labor training issues, migration of health workers, the level of economic development in a country and sociodemographic, geographical and cultural factors 
(31). The number, distribution and composition of health workers available in a country are a key indicator of that country's capacity to provide medical care.

Education and training of the workforce are key to providing the necessary human resources to deliver health services. New and innovative opportunities for education and training in the workplace can ensure that the workforce is prepared and competent for the functioning of a successful health system. The introduction of new technologies in medicine, and especially artificial intelligence, generates the need for constant acquisition of new competencies, which on the one hand will meet the needs of the country, and on the other - will make it an attractive place for treatment of foreign patients and attracting investment. In Bulgaria, like the countries of Central and Eastern Europe (former socialist countries), the migration of health workers is of great importance for the efficient and modern functioning of the health system. The migration model can be strongly manifested in the interior of a country and create a serious imbalance of human resources. This process is typical of each country and has existed for many years (32).

Its regulation requires better workforce planning, attention to remuneration issues and overall human resource management. In many countries, additional pay, accommodation of medical specialists, opportunities for job rotation are used. These are measures that are also needed to address the particularly difficult issue of emigration of health workers, mainly due to low motivation and low wages. As of January 1, 2021, the starting salary of young doctors is only BGN 1,150 (EUR 587), and that of nurses is BGN 950 (EUR 485). This is much lower than the average wage in the EU (Ministry of Labor and Social Policy).

The free movement of people within the EU in the field of health exacerbates the problem. According to the Ministry of Health, nearly 50\% of the doctors and health care professionals who leave the country are between 46 and 60 years old.

In terms of insurance with medical specialists, Bulgaria still occupies positions well above the
DIMITROV S., et al. average for the EU countries. However, the age structure of workers outlines growing deficits in the future. The National Health Strategy 2020 states that "the regional distribution of medical professionals is disproportionate and unbalanced, which leads to difficult access of the population to health care, worsens the quality of medical care and affects the efficiency and effectiveness of medical work (33).

Bulgaria has a very good educational system in the field of medical education. The law on the establishment of a medical faculty at Sofia University was adopted by the 17th National Assembly on 10.11.1917. the oldest medical school in Bulgaria.

In 2021, 11 higher education institutions in Bulgaria are accredited to provide educational services and train professional bachelors, bachelors and masters in the field of higher education. 7. Healthcare and sports in the following professional fields: 7.1 Medicine; 7.2. Dentistry; 7.3. Pharmacy; 7.4. Public Health; 7.5. Health care; 7.5. Health care; 7.5. Health care. Some of the specialties are studied in the professional colleges at the respective medical universities: Medical College „Yordanka Filaretova“" - Sofia (Medical University, Sofia), Medical College - Varna, Vratsa, Pleven, Plovdiv, Burgas and Stara Zagora.

The formula ,localization index (IL)

" is used to determine the health specialization and the place of tourism in the local economy or as a part of the national one. It helps to determine the health specialization and to find the place of tourism in the system of the local, regional or national economy. The localization index is an important indicator in tourism analysis, along with a number of other mathematical methods and models.

$$
\mathrm{IL}=\underline{\mathrm{Sj}: \mathrm{S}},
$$

where, $\mathrm{Sj}$ is the number of physicians in the index area; $\mathrm{S}$ is the number of employees in the tertiary sector in the index area; $\mathrm{Nj}$ is the number of doctors in Bulgaria; $\mathrm{N}$ is the number of employees in the tertiary sector of Bulgaria.

and therefore, where $\mathrm{Sj}$ is the number of people employed in the tourism sector in the index area; $\mathrm{S}$ is the number of employees in the tertiary sector 
in the index area; $\mathrm{Nj}$ is the number of employees in the tourism sector of Bulgaria; $\mathrm{N}$ is the number of employees in the tertiary sector of Bulgaria. When the index is above 1 , it means that the sector is leading, specializing in the region.

Bulgaria is divided into 28 districts. Of these, 5 have an index above (Figure 2), which means
DIMITROV S., et al that they specialize in health. Tourism plays a leading role in 8 of the areas (Figure 3), for which of course there is an explanation. These are the areas with the greatest tourist potential and significant opportunities for the development of health tourism.

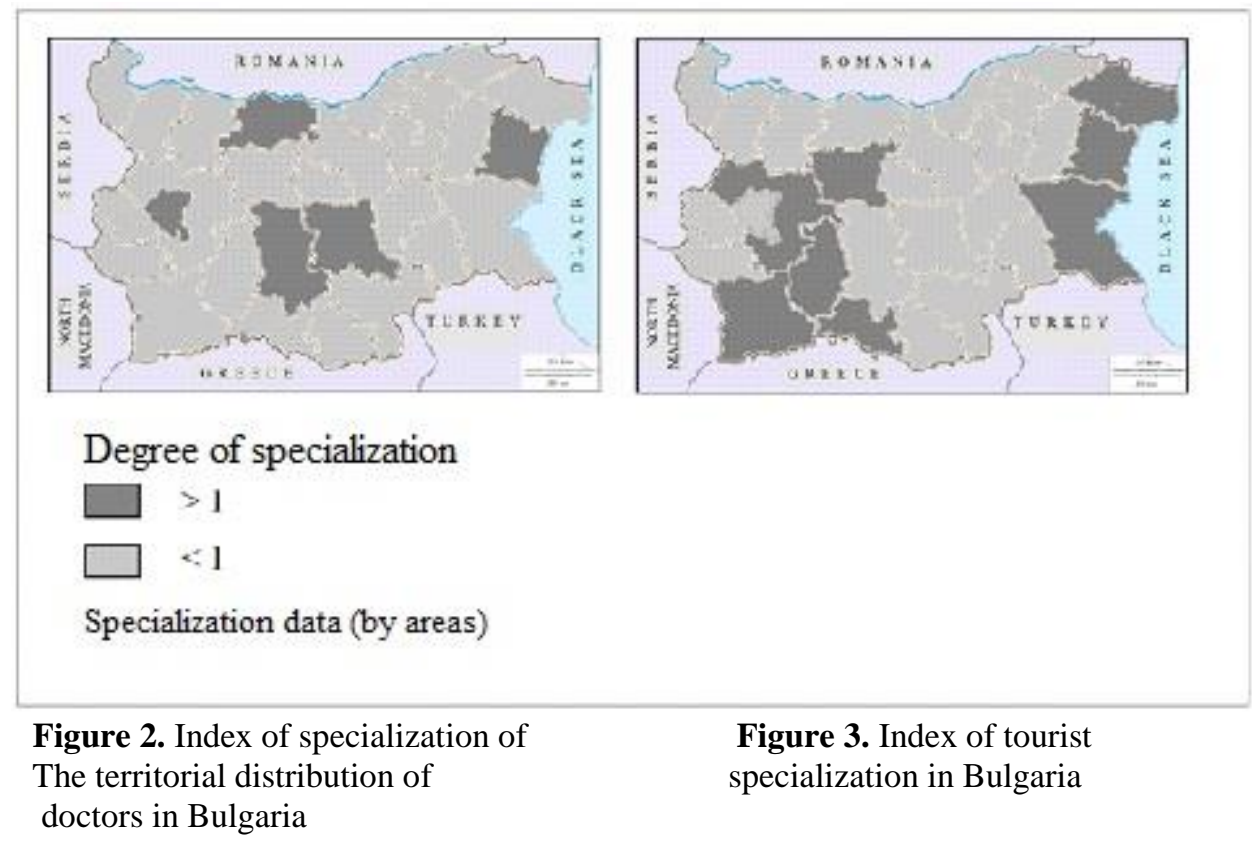

Own production. Source: NSI, 2021.

The regulated professions for which education in healthcare is received are as follows (34): doctor, dentist, pharmacist, medical assistant, midwife, dental technician, public health inspector, physiotherapist, masseur (for the visually impaired), nurse, medical laboratory assistant, orthopedic technician, assistant pharmacist, Xray laboratory assistant, rehabilitator, paramedic. Lecturer in practice in the specialty of the professional field „Health Care“.

Medicine (code 7.1) is studied in 7 universities, of which the admission for 2019-2020 at the Burgas University „Assen Zlatarov“ will be for the first time. Dental medicine invariably in three decades (Medical Universities Sofia, Varna and Plovdiv). In almost all of the above universities specialties are studied in 7.5. Health care.

While in 20011367 professional bachelors, 169 bachelors and 1373 masters graduated (total: 2909), in 2010 the professional bachelors graduated 480, bachelors - 1028, and masters 1981 (total: 3489), in 2016 There are 674 graduates of professional bachelors, 1167 bachelors and 2264 masters (total: 4105), and in 2020 there are 655 professional bachelors, 974 bachelors and 2662 masters (total: 4 291), which shows a steady increase in the number of bachelors and masters graduates. The total number of graduates in 2020 in the three degrees is $47.5 \%$ more than in 2001 and $22.9 \%$ more than in 2010 .

In the period there is a serious growth in the graduates of professional field 7.0 Health and Sports in bachelor's degree $13.5 \%$ growth and in master's degree $16.6 \%$.

It can be summarized that there is a steady growth in graduates in PN 7.0, which allows to sufficiently provide trained the necessary number and professional structure of staff for the health sector. 
In the period after 2001, opportunities for training in the field in new universities were opened, the latest decision is from 2019 for the introduction of training in medicine (7.1) and health care at the University of Burgas „Assen Zlatarov“.
The regional disparities in staff training are also impressive. Five of the training units are located in the South-West region, and in the other regions there is one training unit each (Figure 4).

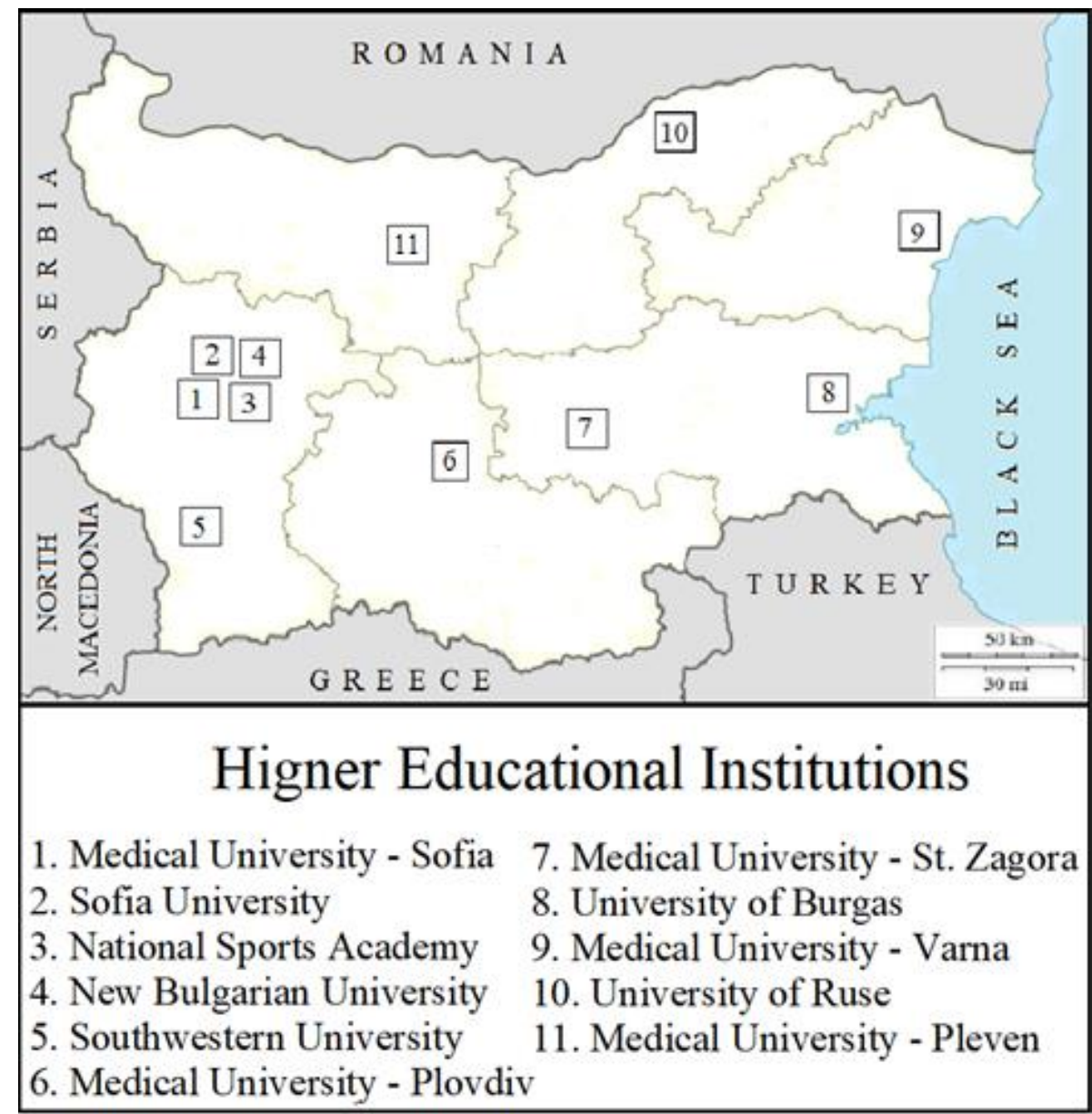

Figure 4. Accredited higner education institutions that provide educational services and train professional bachelors, bachelors and masters in the field of higner education 7. health and sports (according to admission 2021-2022)

Own production. Source: Decision № 437 of 02.06.2021 of the Council of Ministers for approval of the number of students and doctoral students admitted to study in the state higher schools and scientific organizations of the Republic of Bulgaria in the academic year 2021 2022 (published on 07.06.2021).

Another positive side is related to the further diversification of education in the field of higher education. 7. Health and sports. Along with the traditional professions of medicine, dentistry, pharmacy, and resp. Nurses, midwives, laboratory technicians, dental technicians, etc. education for rehabilitators is expanding.
A new master's program „Rehabilitation, sea treatment, wellness and SPA" at the Faculty of Public Health has been opened at the Medical University - Varna, as well as „Kinesitherapy“ bachelor at Medical University Sofia, „Medical Rehabilitation and Occupational Therapy“ master at Medical University Pleven.

Established in 1991 at the National Sports Academy, the Faculty of Kinesitherapy, later renamed Kinesitherapy, Tourism and Sports Animation, has established itself as a leading educational structure in kinesitherapy, physical therapy and rehabilitation, SPA culture, hydro, litho and thalassotherapy. practices. These 
specialties are in response to the development of the health tourism sector in Bulgaria and have the capacity to be developed, diversified and improved. Currently, kinesitherapists are trained not only at the NSA, but also at the Medical University in Sofia, at the Southwestern University and at the University of Ruse.

New specialties appear in response to the development of new products on the health tourism market such as „Medical Rehabilitation and Occupational Therapy" at the Medical University of Pleven. In 2014, the Medical College at the Thracian University in Stara Zagora opened a specialty „Geriatric Care“ and „Paramedicine“.

In addition to the university educational infrastructure, Bulgaria has a good base for education and training in new specialties, which are related to the development of new forms of health tourism in our country. In addition, the Bulgarian education system in the field of healthcare is characterized by the high quality of the human factor. Territorially Medicine, Pharmacy and Dentistry are the professional fields in which students with the highest success from the diploma for secondary education are admitted, as well as the three fields with the largest share of foreign students. In the last few years, the number of medical students is ahead of even law students in Bulgaria. The interest is due, on the one hand, to the observed need on the labor market, and on the other - to the excellent realization (almost 100\%) of the graduates in these professional fields. Against the background of the observed decline in the total number of students in Bulgaria, in the field of health care there is a steady interest and increase in the number of students. According to the data from the rating system of the higher schools in Bulgaria, from its establishment until now, regardless of the higher school in which they graduated medicine, all have excellent professional realization, and the unemployment rate is below $1 \%$. Undisputed scientists in their field teach in vocational education (35).

Nevertheless, the sites that develop and offer SPA tourism in Bulgaria face problems with meeting the mandatory requirements for professional and language qualification of staff, which must be met in accordance with Ordinance 2/29.01.2016
DIMITROV S., et al on the terms and conditions for certification of the centers.

\section{TRAINING}

Clients of health tourism, and especially medical tourists, have different needs compared to local patients. At the heart of appropriate care for medical tourists is the need for an institutional awareness of the unique differences between local patients and medical tourists. A better understanding of what medical tourists and their doctors at home expect from the host hospital or clinic in the medical destination will lead to a better quality of care for medical travelers.

Many hospitals and clinics have little or no training for service and professional staff in relation to the various care that medical tourists need. They often turn to customer service agents who offer tourists airport transportation, an international choice of on-site menu, patient safety, cost-cutting suggestions and other unique offerings accompanied by friendliness and a smile. competencies should be part of the ongoing professional training of employees in the field of health and especially medical tourism.

According to the Health Act, medical education must ensure and guarantee the volume and quality of training of medical specialists, as well as of non-medical specialists working in the national health care system. It defines the basic principles in conducting medical education duration and high quality of teaching with the acquisition of a guaranteed amount of theoretical knowledge and practical skills, phasing and continuity of education, the right to choose a specialty.

Postgraduate education is the right of all persons with educational qualification degrees „Doctor“, „Master" and „Bachelor" who work in the national health care system. It includes both training for acquiring a specialty in healthcare and continuing medical training.

The Minister of Health annually determines the number of places for postgraduate education in specialties subsidized by the state and in accordance with the goals and priorities of the national health strategy. He plans and coordinates the activities for conducting the postgraduate training for acquiring a specialty by the medical 
specialists with non-medical education, working in the national health care system.

Theoretical training for acquiring a specialty in health care is conducted by higher education institutions that have received a positive accreditation assessment in health care, in the Military Medical Academy and the national centers for public health, accredited in the respective specialty by health care, and practical training - in medical institutions that have received a positive accreditation assessment for training of students and graduates.

The acquisition of a degre of professional qualification is carried out in accordance with the Vocational Education and Training Act. The system of vocational education and training prepares citizens for realization in the economy and in other spheres of public life, creating conditions for acquiring professional qualification and for its continuous improvement (36).

Vocational education and training in the system of Bulgaria according to Art. 18 of the VETA is implemented in the following institutions: vocational schools, vocational high schools, vocational colleges, vocational training centers, information and vocational guidance centers, training centers for trainers.

Vocational schools carry out the initial vocational training by acquiring the first and second degree of professional qualification and qualification in part of the profession with a duration of up to four years. Such are the acquisition of the profession „Health Assistant", „Nurse“, „Paramedic“, „Assistant Dentist“, „Eye Optics Technician“, „Performer of thermal procedures" (Performing thermal procedures in balneological and other rehabilitation centers) and others. In Bulgaria, accurate available statistical information is not maintained and a correct assessment of this resource cannot be made.

Vocational high schools may also provide vocational education for obtaining a qualification in part of the profession with a duration of up to 4 years, as well as vocational education with the acquisition of a second degree of professional qualification lasting four years or a third degree lasting four or five years.
DIMITROV S., et al.

Apart from the vocational schools in Bulgaria, training in the profession „Paramedic" is planned to be offered to registered as unemployed persons who meet the requirements for inclusion in the training. The training is funded by the National Budget of Bulgaria and is conducted in specialized centers. There is also a practical part in hospitals.

The centers for continuing education conduct trainings in the profession „Health Assistant" (SPPOO Code 723010), „Nurse“ (SPPOO723020 Code), "Contractor of thermal procedures in balneological and other rehabilitation centers", „Health Care“ (SPPOO Code 7230101 Assistant to a dentist (SPPOO code 7240101) and others.

\section{NEED FOR COMPETENCIES IN HEALTH TOURISM}

Employment in health-related occupations, such as health tourism, has increased by $12 \%$ over the last decade and is expected to increase by about $10 \%$ by 2025 (37). Traditionally, the majority of health professionals have intermediate qualifications. The five key skills, according to Cedefop's Skills Panorama, needed for these workers are:

1. teamwork, 2. communication, 3. problem solving, 4. Learning, 5. work-specific skills. These skills could support employees in their employment to meet future skills challenges. The study predicts that the expected increase in the employment of health professionals over the next decade is unlikely to come from the healthcare sector.

Europe's aging population is increasing the challenges facing public health policies and, consequently, the demand for health professionals. It is believed that lifestyle changes have a strong impact on the types of diseases that associates will increasingly manage and treat.

Skills Panorama brings out the following drivers of change that will lead to the need for new skills in the health sector:

- Aging population: Patients often feel safer at home and it is best not to travel to and from outpatient wards. Tele-health solutions not only benefit patients in terms of avoiding unnecessary, sometimes burdensome transport - they are also cost-effective for society as a whole. Video conferencing, home monitoring; 
- Lifestyle changes have a strong impact on the types of diseases and healthcare professionals will increasingly have to know, manage and treat them. Collaboration skills are paramount;

- Preventive practice requires specific experience in health promotion activities across the EU;

- Technological advances are changing the way patients understand their own health needs and enabling healthcare professionals to provide more human-centered care. Associate professionals, such as nurses and technicians who need technical skills and experience in various emerging practices;

- Emerging practices such as e-health (provision of health care facilitated by electronic processes and devices) and $\mathrm{m}$-health;

- Fiscal challenges (38).

The main competencies in which there are deficits on the Bulgarian market and which must be acquired for the health tourism sector as a whole and on which trainings must be carried out are at least the following: Quality of the medical service and management of the results; International patient management; International patient marketing; Patient safety, security and transparency; The unique needs of the medical tourist (visitor); Hospital leadership and management skills; Operations and infrastructure; Follow-up care management; Dispute resolution /conflicts; Multicultural influences/ differences at all levels of staff.

In 2018, the Ministry of Tourism signed an agreement with the Ministry of Labor and Social Policy to promote the provision of training for the acquisition of professional qualifications, including through on-the-job training. The trainings will be predominantly carried out in the state enterprise „Bulgarian-German Center for Vocational Training" in its centers in Tsarevo and Smolyan.

Nadezhda Hospital has also received certification to be the main training center of the International School of Laser Gynecology. The mission of the International School is to enable gynecologists around the world to introduce laser technology to their routine practice. With the start of operation of the first training center of Medical University, based at Nadezhda Hospital in Sofia in 2019, the beginning of a larger international exhibition of Bulgaria as a destination, which trains and
DIMITROV S., et al

respectively provides for their needs these specialists.

\section{RESULTS AND CONCLUSION}

From what has been said so far, we can draw the following conclusions:

There is a positive desire to restore the image of Bulgaria as a destination for balneology (medical SPA). The availability of various opportunities for tourism development in Bulgaria has a positive effect on the demand for health services (cultural, sea and nature tourism, SPA, SPA medical (balneo), wellness, thalassotherapy, etc.). The country has an excellent accommodation base in wonderful rehabilitation centers and the favorable influence of climatic conditions, beautiful and often pristine natural environment for the recovery period of treatment. There are opportunities for combining with other types of specialized and traditional tourism and more harmonious development of tourist areas as a main and additional specialization;

There are well-equipped medical and health medical facilities, incl. public and private, close to quality health natural resources and excellent conditions for physical therapy and rehabilitation. This ensures a high level of treatment security: the number of beds /capita is one of the highest in the EU. There are excellent private medical and health facilities and offices for dental tourism, and the quality/ price ratio of medical services is very good. Easy access to treatment without long waiting lists is provided and there is a possibility to combine hospital treatment with a recovery period and a rehabilitation period - both medical services and rehabilitation therapy. This leads to the extension of the tourist season and the implementation of year-round medical and dental tourism, kinesitherapy and rehabilitation;

The staffing is very good. Excellent medical specialists have been trained and achieved in the field of cardiology, cardiac surgery, microvascular surgery, liver surgery, invasive cardiology, orthopedics, neurology, maxillofacial surgery, ophthalmology, neuroradiology and nutrition, oncology. A policy is being pursued to attract a larger number of candidate students (Bulgarians and foreigners) in specialties related to spa tourism and rehabilitation;

There is a desire for new educational programs and improvement of educational documentation in response to the development of the tourist 
product and achieving a higher degree of compliance between the qualification characteristics, curriculum and the peculiarities of the professional field.

There is a tendency for growth in the graduates in the three levels of higher education in the Professional fields 7.1. Medicine, 7.2. Dentistry, 7.3. Pharmacy, 7.4. Health care, 7.5. Kinesitherapy and rehabilitation. The number of students in the professional field of area 7.0 is also increasing, which allows to sufficiently provide staff trained with the necessary number and professional structure for the healthcare sector.

The establishment of areas with health and tourism specialization will allow overcoming the regional disparities in staff training. The diversification of the specialized medical education is carried out. The training of staff in the field of health tourism is carried out not only in public schools, but also in specialized centers that meet the criteria for state educational requirements.

\section{REFERENCES}

1. The concept for tourist zoning of Bulgaria. Ministry of Tourism, Sofia, 2015.

2. Stancova, M., Stability and innovation in the management of spa tourism in Bulgaria. Management and sustainable development, University of Forestry, Sofia 1-2 / 2006 (14):459-465.

3. Yordanov, J., Problems and perspectives in the development of the Bulgarian health, spa and wellness tourism. Management and Sustainable Development. University of Forestry, Sofia, 3-4 / 2008 (21):167-173.

4. Shishmanova, M., Mineral waters, balneotherapy and regional policy. Greening. New Bulgarian University, Sofia:39-46, 2011.

5. Vasileva, M., Conceptual framework of spa and wellness tourism in Bulgaria. PhD Thesis, Southwestern University "Neofit Rilski“, Blagoevgrad, 2012.

6. Rizova, T., Management and organization of the use of the mineral water resources of Bulgaria for health tourism. PhD Thesis, New Bulgarian University, Sofia, 2013.

7. Kazandzieva, V., Trends in the development of spa and wellness tourism. International
DIMITROV S., et al. tourist forum „Spa and Wine”, Southwest University „Neofit Rilski”:173-177, 2014.

8. Stoynev, P., Status and development of health tourism in Bulgaria. $\mathrm{PhD}$ Thesis. Sofia University, 2015.

9. Spasova, St., Investments in real estate for balleology and spa tourism in the Republic of Bulgaria. PhD Thesis, Varna University of Economic, 2016.

10. Stoyanova, M., Index of localization of SPA and wellness hotels in Bulgaria by planning regions. Proceedings scientific conference „Geographical aspects of the planning and use of the territory in the conditions of global changes", Varshets, September 23 September 25, 2016.

11.Staykov, K., Georgieva, P., Models for financing healthcare: Opportunities for Bulgaria, Institute for Market Economics. Friedrich Naumann Foundation for Freedom:1-32, 2018.

12. Vladeva, E., Contemporary trends of Spa and Ulenes tourism in Bulgaria. Varna Medical Forum, Medical University - Varna, vol. 7, 2018, issue 2:149-152.

13. Veselinova, N., Medical geography achievements and hopes. Paradigma Publishing House, 2021.

14. Belichenova, T., „Medico-geographical analysis of the potential for balneotherapy and climatotherapy in the municipality of Velingrad as a factor for local development". PhD Thesis, Sofia University „St. Kliment Ohridski”, 2021.

15. Updated National Strategy for Sustainable Tourism Development in the Republic of Bulgaria, 2014-2030. Ministry of Tourism, 2014.

16. World tourizm organozation. UNWTO World Tourism Barometer, 2021.

17. Health tourism. Product analysis. „Esklipika Global Metric", Ministry of Tourism. Sofia, 2019.

18. Mainil, T., Eijgelaar, E., Klijs, J., Navijn, J., and Peeters, P., Research for TRAN Committee Health tourism in the EU: a general investigation, European Parliament, Policy Department for Structural and Cohesion Policies, Brussels, 2018.

19. Trends in polish healthcare (2017). https://www.pwc.pl/pl/pdf/trends-in-polish-

healthcare-2017- en-pwc.pdf (accessed 15.08.2021).

20. Mainil, T., Eijgelaar, E., Klijs, J., Navijn, J., and Peeters, P., Research for TRAN Committee - 
Health tourism in the EU: a general investigation. European Parliament, Policy Department for Structural and Cohesion Policies, Brussels, 2018.

21. National health strategy 2020. Ministry of Health, Sofia, 2015.

22. Health tourism. Product analysis. „Esklipika Global Metric“, Ministry of Tourism. Sofia, 2019.

23. Neshkov, M., Tourism policy. Historical transformations, current state and directions for development in Bulgaria, Ed. Science and Economics, Varna University of Economics, 2012.

24. National strategy for sustainable tourism development in the Republic of Bulgaria 20092013. State Agency for Tourism, Sofia, 2009.

25 . World health organization. World health report. Shaping the Future Geneva, 2003.

26. Veleva, N., Status and trends in the labor market of nurses in Bulgaria. PhD Thesis, Sofia University, 2013.

27.https://ec.europa.eu/eurostat/databrowser/view/t ps00045/defult/table?lang=en (accessed 15.08.2021).

28.EUROSTAT. Healthcare personnel statistics dentists, pharmacists and physiotherapists. Statistics Explained, 2018.

29. Health tourism. Product analysis. „Esklipika Global Metric“, Ministry of Tourism. Sofia, 2019.
DIMITROV S., et al

30. Khatri, N., Pasupathy, K., Hicks, L., The crucial role of people and information in health care organizations. Strategic Human Resource Management in Health Care, Emerald Group Publishing Limited:195-211, 2010.

31. Kabene, S., Orchard, C., Howard, J., Soriano, M., and Leduc, R., The importance of human resources management in health care: a global context. Human Resources for Health, 4, 20:117, 2006.

32. Health tourism. Product analysis. „Esklipika Global Metric", Ministry of Tourism. Sofia, 2019.

33. National health strategy 2020. Ministry of Health, Sofia, 2015.

34. NACID (2021): Regulated professions by categories

http://nacid.bg/sites/qual/index.php?id=24/14.0 8.2021

35. Health tourism. Product analysis. „Esklipika Global Metric", Ministry of Tourism. Sofia, 2019.

36. https://www.navet.government.bg/bg/spisakna-profesiite-za-poo/ review on (accessed 20.08.2021).

37. CEDEFOR. Skills Panorama: Health associate professionals: skills opportunities and challenges:1-5, 2019.

38. Health tourism. Product analysis. „Esklipika Global Metric", Ministry of Tourism. Sofia, 2019. 